\title{
Study on Product Dealers Service Quality Function Based on Uncertain Multiple Attribute Decision Making
}

\author{
Zhenqiang Jian \\ Economics and Management School of Wuhan University \\ Zzjian@126.com
}

\begin{abstract}
This paper, according to the characteristics of the goal and criteria in decision making for product design alternatives, provides an evaluation model combining UEOWA process with preference ranking organization method for enrichment evaluations. Preference ranking organization method for enrichment evaluations is used to calculate the net flow to obtain the ranking of the design alternatives based on the combination of quantitative and qualitative decision criteria system. This approach takes into account the uncertainty of the attribute information and orients to the designer's goals and values, thus has certain implication in product design. The method can be provide reference for this kinds of problems.
\end{abstract}

\section{Introduction}

Quality function deployment is a systematic, structured method for product development and quality management to realize customer requirements throughout the whole process of its application in the form of sequential decision. The decision information is centralized and the decision process is transparent. With the normalization of its important processes, the method can be self-documenting. Currently, product market competition continues to accelerate, the diversification and personalization of customer requirements has already become the trend, product/service development is becoming increasingly complex, thus quality function deployment has a good practical significance and application prospects [1-3].

The process of quality function deployment is the processing flows of information. From the original customer requirements, all the relevant information is collected and handed to refine the required design knowledge to support the subsequent decisions. The vagueness and complexity of knowledge, the diversity and uncertainty of the information form, and the special needs of knowledge for decision making hinder the implementation of quality function deployment. The Uncertain Multiple Attribute Decision Making methods are technical decision aids for evaluating alternatives characterized by multiple attributes under uncertain environment, which has intrinsically close contact with many problems of quality function deployment [4]. This research combines the Uncertain Multiple Attribute Decision Making methods to explore some key issues in quality function deployment. We hope our research can help this effective method better adapt to the uncertainty environment, enrich and improve the quality function deployment methodology, and provide technical support for the development of product/service in manufacturing firms. The major achievements and innovations of this dissertation are summarized as follows:

\section{Problem Description}

There are some decision-makers evaluated the each index of some programs but not all in practice. For example, there are many product sellers to sale the same brand electronic products, the consumers as the evaluators who have received services from some 
electronic product sellers to evaluate the service quality of them but not all [5]. There are tourists in the evaluation of scenic spots so that government will get the results to compare the service quality between different scenic spots, and so on. This kind of decision problems described as Figure 1.

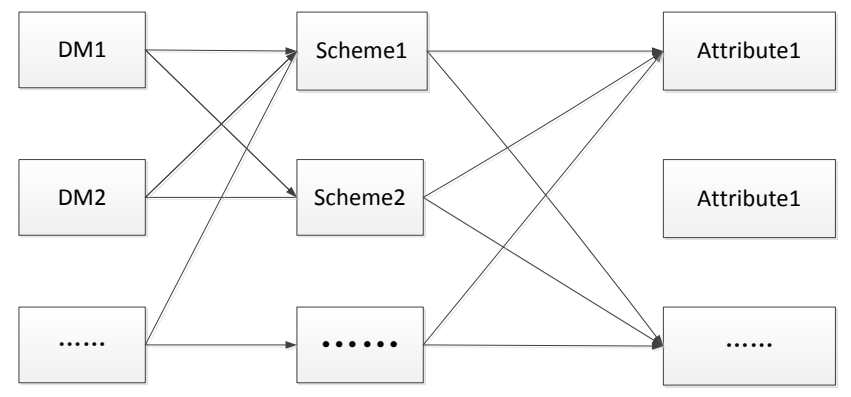

Figure 1:

We use electronic service quality as an example to study such issues in this paper. Electronic mobile manufacturers need to supervise and manage the quality of service to its brand product stores, so they need to compare product sellers service quality scientific [6-8].Because of different sellers have different number of customers, the evaluation results are not deterministic language but the sum of weighted uncertainty language. For example, there are $\mathrm{x}$ customers for one seller, every one evaluate the index of service quality has different results, so we can't use the deterministic language to demonstrate the overall evaluation results for each index. The problem described as bellow: all of customers for one seller to evaluate the service quality, then combined all of results for different sellers to form the service quality evaluation matrix for all sellers. Assume that there are $\mathrm{m}$ sellers in market, for the $\mathrm{i}_{\mathrm{th}}(\mathrm{i}=1,2 \ldots \mathrm{m})$ seller, $n_{i j}{ }^{k}$ is the number of consumers who evaluate the $j_{\text {th }}$ index value as $s_{k}$, so the evaluation result matrix for the $i_{\text {th }}$ seller is

$$
\left.\mid \begin{array}{cccc}
n_{i 1}^{0} & n_{i 2}^{0} & \ldots & n_{i j}^{0} \\
n_{i 1}^{1} & n_{i 2}^{1} & \ldots & n_{i j}^{1} \\
\cdots & \ldots & \ldots & \\
n_{i 1}^{k} & n_{i 2}^{k} & \ldots & n_{i j}^{k}
\end{array}\right\}
$$

So the evaluation results of $j_{t h}$ index by all consumers record as the sum of weighted deterministic language as follow:

$$
\begin{aligned}
P_{i j}= & n_{i j}^{0} s_{0}+n_{i j}^{1} s_{1}+n_{i j}^{2} s_{2}+n_{i j}^{3} s_{3}+\ldots+n_{i j}^{k} s_{k} \\
R= & \left\lceil\begin{array}{cccc}
p_{11} & p_{12} & \ldots & p_{1 j} \\
p_{21} & p_{22} & \ldots & p_{2 j} \\
\ldots & \ldots & \ldots & \ldots \\
p_{m 1} & p_{m 2} & \ldots & p_{m j}
\end{array} \mid(i=1,2 \ldots m) ;\right.
\end{aligned}
$$

$\mathrm{k}$ is the number of index, and the number of comsumers is $n_{i}=n_{i j}^{0}+n_{i j}^{1}+\ldots \ldots+n_{i j}^{k}$; $\mathrm{p}_{\mathrm{ij}}=\mathrm{P}_{\mathrm{ij}} / \mathrm{n}_{\mathrm{i}}$; 
$p_{i j}$ is the weighted mean of the $j_{t h}$ index value that evaluate by all the consumers for $i_{\text {th }}$ seller, so we constructed the service quality evaluation matrix $\mathrm{R}$ of all the product sellers by consumers as follow:

\section{Basic Knowledge}

Two-tuple linguistic information is reprenst by tuple group $\left(\mathrm{s}_{\mathrm{k}}, \alpha\right)$ that show the results for evaluation objects. $s_{\mathrm{k}}$ is the element of properties language assessment scale set.

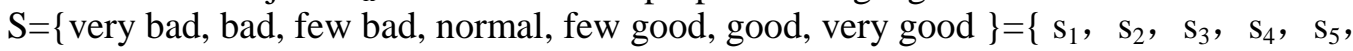
$\left.\mathrm{s}_{6}, \mathrm{~s}_{7}\right\}$;

$\mathrm{S}$ has some properties as follows:

(1) order:when $\mathrm{i}>=\mathrm{j}, \mathrm{s}_{\mathrm{i}}>=\mathrm{s}_{\mathrm{j}}$

(2) inverse operator: $\operatorname{Neg}\left(\mathrm{s}_{\mathrm{i}}\right)=\mathrm{s}_{\mathrm{j}}, \mathrm{j}=\mathrm{L}-\mathrm{i}, \mathrm{L}+1$ is the element number of laguage $\operatorname{set}(\mathrm{S})$.

(3) maximation operation and minimization operation: when $\mathrm{s}_{\mathrm{i}}>=\mathrm{s}_{\mathrm{j}}, \min \left\{\mathrm{s}_{\mathrm{i}}, \mathrm{s}_{\mathrm{j}}\right\}=\mathrm{s}_{\mathrm{j}}$

In order to avoid loss decision-making information and calculation, we defined a extended scale $S=\left\{s_{i} \mid s_{1} \leq s_{i} \leq s_{t}, t \in[1, t]\right\}$, which was based on original scale $S=\left\{s_{i} \mid i=1,2,3 \ldots q\right\}$.t is a sufficiently large positive number, if $i \in\{1,2,3 \ldots q\}$, we called $\mathrm{s}_{\mathrm{i}}$ is primitive term, otherwise, $\mathrm{s}_{\mathrm{i}}$ is expand term. Decision makers use primitive term to evaluate programs usually, but use expand term in the procedure of calculation and order.

If $s=\left[s_{\alpha}, s_{\beta}\right], s_{\alpha}, s_{\beta} \in S, s_{\alpha}$ and $s_{\beta}$ showed lower limit and upper limit especially, and defined $s$ as the sets of all the uncertainty language variables.

Definition 1: on the basis of the ordering of language evaluation scale, if $\mathrm{k}$ consumers evaluation results is $\mathrm{s}_{\mathrm{i}}$, consumers evaluation results is $\mathrm{s}_{\mathrm{j}}$, so the total evaluation value of $\mathrm{k}+\mathrm{l}$ consumers is $\mathrm{s}_{(\mathrm{k}+\mathrm{l}+\mathrm{j}) /(\mathrm{k}+\mathrm{l})}$, it is between $\mathrm{s}_{\mathrm{i}}$ and $\mathrm{s}_{\mathrm{j}}$, we assumed $k s_{i}+l s_{j}=s_{(k i+l j) /(k+l)}$, when $\mathrm{j}<=\mathrm{i}, \quad j \leq \frac{k i+l j}{k+l} \leq i$.

Property 1: if $k$ consumers evaluate one index value as $s_{i}$, so the overall index value is $s_{i}$, and we can deem $\mathrm{ks}_{\mathrm{i}}$ is equivalent to $\mathrm{s}_{\mathrm{i}}$, record as $\mathrm{ks}_{\mathrm{i}}==\mathrm{s}_{\mathrm{i}}$

Property2: Extended to the entire expand scale,

$$
k_{1} s_{i}+k_{2} s_{j}+\ldots \ldots+k_{x} s_{h}=s_{\frac{k_{1} s_{i}+k_{2} s_{j}+\ldots \ldots+k_{x} s_{h}}{k_{1}+k_{2}+\ldots \ldots . k_{x}}} s_{i}, s_{j,} s_{k} \in \bar{S}
$$

Definition 2: Order int is the rounding operator, $\operatorname{int}\left(\frac{k_{1}+k^{2}+\ldots \ldots . k_{x}}{k_{1} s_{i}+k_{2} s_{j}+\ldots . .+k_{x} s_{h}}\right)$ is the integer part of $s_{k_{1} s_{i}+k_{2} s_{j}+\ldots . .+k_{x} s_{h}}$

Definition 3: Assumed $s_{a}$ is belong to extended scale and a is a real number between 1 and $t$. if ais a integer, $s_{a}$ is expressed as uncertainty language $\left[s_{a}, s_{a}\right]$;but if a is not a integer, $\mathrm{s}_{\mathrm{a}}$ is expressed as uncertainty language [int(a),int(a)+1] according to definition 2 .

Definition 4: For any two uncertain linguistic variables, $u=\left[s_{a}, s_{b}\right], v=\left[s_{c}, s_{d}\right] \in S$, $\beta, \beta_{1}, \beta_{2} \in[0,1]$,the operation rule was Defined as follows:

(1) $u \oplus v=\left[s_{a}, s_{b}\right] \oplus\left[s_{c}, s_{d}\right]=\left[s_{a} \oplus s_{c}, s_{b} \oplus s_{d}\right]$

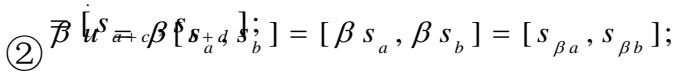


(3) $u \oplus v=v \oplus u$;

(4) $\beta(u \oplus v)=\beta u \oplus \beta v$;

(4) $\left(\beta_{1}+\beta_{2}\right) u=\beta_{1} u \oplus \beta_{2} u$

Definition 5: Assumed $\tilde{u}=\left[s_{a}, s_{b}\right], \tilde{v}=\left[s_{c}, s_{d}\right] \in \tilde{S}$ and defined the possible degree of the formula $l_{a b}=b-a, l_{c d}=d-c$ as follows:

when $\tilde{u} \geq \tilde{v} ; p(\tilde{u} \geq \tilde{v})=\max \left\{1-\max \left(\frac{d-a}{l_{a b}+l_{c d}}, 0\right), 0\right\}$, when $\tilde{v} \geq \tilde{u} ; p(\tilde{v} \geq \tilde{u})=\max \left\{1-\max \left(\frac{l_{a b}+c^{c d}}{l_{a b^{\sim}}+l_{c d}}, 0\right), 0\right\}$,

Definition 6: Assumed $u=\left[s_{a}, s_{b}\right], v=\left[s_{c}, s_{d}\right], \gamma=\left[s_{e}, s_{f}\right] \in S$ there are some conclusions according to definition 5 as follows:

(1) $0 \leq p(\mathrm{u} \geq \mathrm{v}) \leq 1,0 \leq p(\mathrm{v} \geq \mathrm{u}) \leq 1$.

(2) when only $\mathrm{d} \leq a, p(\mathrm{u} \geq \mathrm{v})=0 \quad p(\mathrm{u} \geq \mathrm{v})=1$;

when only $\mathrm{b} \leq c, p(\mathrm{v} \geq u)=1$

(3) when only $\mathrm{b} \leq c$; when only $\mathrm{d} \leq a, \quad p(\mathrm{v} \geq \mathrm{u})=0$

(4) $p(\mathrm{u} \geq \mathrm{v})+p(\mathrm{v} \geq \mathrm{u})=1, p(\mathrm{u} \geq \mathrm{u})=1 / 2$.

(5)when only $\mathrm{a}+b \geq c+d, p(u \geq v) \geq 1 / 2$;

when only $\mathrm{a}+b=c+d, p(\mathrm{u} \geq \mathrm{v})=1 / 2$

6)when $p(u \geq v) \geq 1 / 2, p(v \geq \gamma) \geq 1 / 2$, there is a result $p(u \geq \gamma) \geq 1 / 2$

Definition 7: Assumed a function UEOWA: $S^{n} \rightarrow \bar{S}$,

if $\quad U E O W A_{w}\left(u_{1}, u_{2} \ldots, u_{n}\right)=w_{1} v_{1} \oplus w_{2} v_{2} \oplus \ldots \ldots \oplus w_{n} v_{n}, \quad \mathrm{~W}=\left(\mathrm{W}_{1}, \mathrm{w}_{2}, \ldots, \mathrm{W}_{\mathrm{n}}\right)$ is the weighting vector associated with function UEOWA, $w_{j} \in[0,1](j \in N), \sum_{j=1}^{n} w_{j}=1, \tilde{u}_{i} \in \tilde{S}, \tilde{v}_{i}$ is a the $\mathrm{j}_{\mathrm{th}}$ bigger element in the group of uncertain linguistic variables $\left(u_{1}, u_{2} \ldots, u_{n}\right)$, we called function UEOWA operator is a uncertain EOWA operator.

Definition 8: In the sort vector $v_{i}=\frac{1}{n(n-1)}\left(\sum_{1}^{n} p_{i j}+\frac{n}{2}-1\right), \mathrm{n}$ is the order of possible degree matrix, $\mathrm{p}_{\mathrm{ij}}$ is the element of the matrix.

\section{Evaluation INDEXS of Product SELLERS SERVICE QUALITY}

This article from the consumers perspective to study most concerned factors When they accepting car dealers service, as index of the decision-making model [9].

The first index is service environment(SE) which is the rest place provided by car dealers who provide computers for customers to access entertainment and fine magazines 
nd the place whether bring a relaxed atmosphere for customers will to enhance customers feeling because of the good service environment.

Second index is the service attitude (SA) refers to the workers have mild manners, respect and enthusiastic, active, etc. or not in the process of provide services to consumers, rather than passed individual negative emotions to customers. If service attitude is better, the customer will feel better and the possibility will greater for accept service again.

Third index is maintenance quality(MQ),after consumers receive the services, whether there will be some problems make customers feel the quality is not high, such as the consumers to shop for air cleaning work, they find the car air-conditioning still smell after the completion of the service. This situation will make consumers feel poor quality of service.

Fourth index is service professionality(SP), the staff need explain the technology problem and questions to customers professional and easy to understand.

Fifth index is work efficiency(WE), it is refers to response time is or not fast when consumers need service for example, maintenance staff should arrive at the position when consumer's car broke down as soon as possible.

Sixth index is Vehicle cleanliness(VC)that means after complete electronic mobile maintenance if the vehicle exterior and interior are kept clean or cause damage.

The last index is expense(E). Generally, the better the service, the costs are higher, but consumers want lower prices to get higher service levels in a competitive market, if the price is higher than the average too much, even if the dealer offers the best service will also affect consumers evaluation for the overall quality of service [10].

\section{Algorithm Steps}

Step 1 Construct a weighted matrix

Step 2 According the definitions 1, 2, 3, and properties 1 and 2 to transfer the evaluation of the property value with certainty language to property value by uncertain language, and then get a comprehensive decision matrix.

Step 3 According the definitions 5 to compare the property value between different objects and then build possible degree matrix.

Step 4 According the definitions 5to calculate the ordering vector $\mathrm{V}$ of possible degree matrix.

Step 5 According the vector components to descend order by uncertain linguistic properties of each program in the decision matrix.

Step 6 According 7 to use UEOWA operator and weighted vector to assemble uncertain linguistic attribute values which was sorted and obtain a comprehensive attribute value of the scheme d.

$z_{d}(w)(d \in N): z_{d}(w)=U E O W A_{w}\left(u_{1}, u_{2}, \ldots, u_{n}\right)$

Step 7 According definition 5 to reuse the possible degree formula to calculate the possible degree $z_{d}(w)$ between the comprehensive attribute value of different schemes and build complementarity matrix of possible degree.

Step 8 Get the vector of possible degree and sorted according definition 8 , we get a result which object is best. 


\section{Case Study}

A electronic manufacture in order to assess the service quality of four different product dealers and collect some results that there are 146, 108, 206, 176 consumers to evaluate the quality in the same time period respectively, we accord step 1 and step 2 to get table 1 and a comprehensive matrix that described by uncertain language.

Table 1. Transformed Weighted Certain Language to Extended Term

\begin{tabular}{llllllll}
\hline & SE & SA & MQ & SP & WE & VC & E \\
\hline A & $S_{2.698}$ & $S_{1.061}$ & $S_{3.753}$ & $S_{4.061}$ & $S_{2.239}$ & $S_{5.342}$ & $S_{1.164}$ \\
B & $S_{3.027}$ & $S_{4.027}$ & $S_{3.481}$ & $S_{4.518}$ & $S_{3.472}$ & $S_{5.083}$ & $S_{3.407}$ \\
C & $S_{2.990}$ & $S_{3.995}$ & $S_{5.296}$ & $S_{3.990}$ & $S_{4.228}$ & $S_{5.631}$ & $S_{1.587}$ \\
$\mathrm{D}$ & $S_{4.437}$ & $S_{2.772}$ & $S_{4.727}$ & $S_{5.545}$ & $S_{3.852}$ & $S_{5.056}$ & $S_{2.965}$ \\
\hline
\end{tabular}

$$
\left[\begin{array}{lllllll}
{\left[s_{2}, s_{3}\right]} & {\left[s_{1}, s_{2}\right]} & {\left[s_{3}, s_{4}\right]} & {\left[s_{4}, s_{5}\right]} & {\left[s_{2}, s_{3}\right]} & {\left[s_{5}, s_{6}\right]} & {\left[s_{1}, s_{2}\right]} \\
{\left[s_{3}, s_{4}\right]} & {\left[s_{4}, s_{5}\right]} & {\left[s_{3}, s_{4}\right]} & {\left[s_{4}, s_{5}\right]} & {\left[s_{3}, s_{4}\right]} & {\left[s_{5}, s_{6}\right]} & {\left[s_{3}, s_{4}\right]} \\
\mid\left[s_{2}, s_{3}\right] & {\left[s_{3}, s_{4}\right]} & {\left[s_{5}, s_{6}\right]} & {\left[s_{3}, s_{4}\right]} & {\left[s_{4}, s_{5}\right]} & {\left[s_{5}, s_{6}\right]} & {\left[s_{1}, s_{2}\right]} \\
{\left[s_{4}, s_{5}\right]} & {\left[s_{2}, s_{3}\right]} & {\left[s_{4}, s_{5}\right]} & {\left[s_{5}, s_{6}\right]} & {\left[s_{3}, s_{4}\right]} & {\left[s_{5}, s_{6}\right]} & {\left[s_{2}, s_{3}\right]}
\end{array}\right]
$$

According to step 3 and step 4, we get ordering vectors of possible degree as follows:

$V_{l}=(0.131,0.083,0.166,0.196,0.107,0.214,0.083)$;

$V_{2}=(0.060,0.179,0.107,0.179,0.107,0.214,0.107)$;

$V_{3}=(0.095,0.131,0.202,0.131,0.166,0.202,0.071)$;

$V_{4}=(0.155,0.083,0.155,0.202,0.119,0.202,0.083)$;

Assumed weighted vector

$$
\mathrm{w}=(0.10,0.13,0.19,0.23,0.15,0.08,0.12),
$$

And according step 5 and step 6 to calculate the comprehensive evaluation values of attributes for these four decision schemes, as follows:

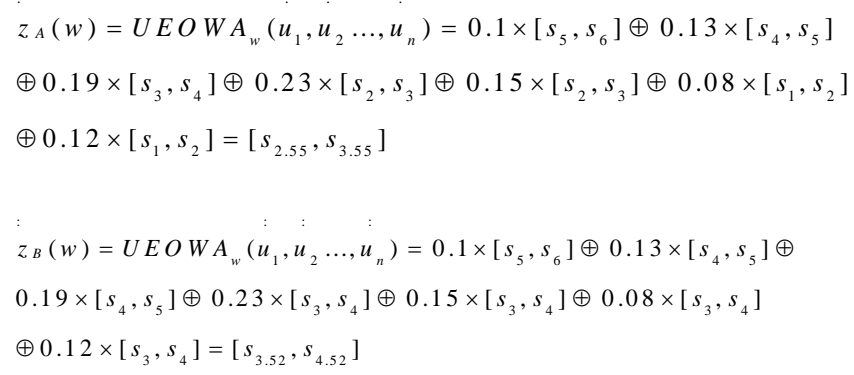




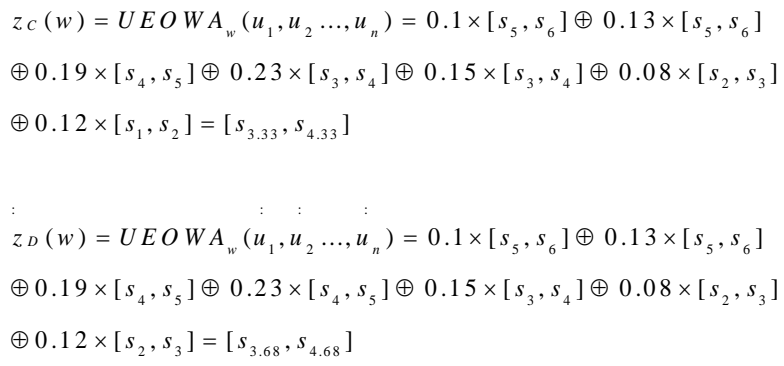

And then according step 7 to use the formula of possible degree to calculate the possible degree matrix between different attribute values of four schemes and get a result as follow:

$\left.\mid \begin{array}{cccc}0.5 & 0.015 & 0.11 & 0 \\ 0.985 & 0.5 & 0.595 & 0.42 \\ 0.89 & 0.405 & 0.5 & 0.325 \\ 1 & 0.58 & 0.675 & 0.5\end{array}\right]$

At last,according step 4 to calculate the ordering vector of possible degree $\mathrm{V}=(0.1354,0.2917,0.1767,0.2296)$ and then get the result $B$ f $D$ f $C$ f $A$, sorted by vector component, so the best one in these car dealers is B.

\section{Conclusion}

To deal with the vagueness and incompleteness of customer preference in customer requirements analysis, a method on the basis of incomplete linguistic judgment matrices to analysis the importance of customer requirements is proposed. Each individual preference is represented by an additive linguistic judgment matrice and extended to a complete form when certain elements are missing. Then all these extended matrices are aggregated into a collective one in order to obtain the importance of customers' requirements. The method can not only solve the problem of information missing in customer surveys, but the method can be provided some consults for this kind of multiple attribute problems.

\section{References}

[1] W. L. Suo, "Method for uncertain linguistic multiple attribute group decision making based on extended VIKOR", Journal of Control and Decision, vol. 28, (2003), pp. 1431-1435.

[2] G. W. Wei, "Method of uncertain linguistic multiple attribute group decision making based on dependent aggregation operators", Journal of Systems Engineering and Electronics, vol. 32, (2010), pp. 764-768.

[3] W. F. Liu and D. X. Wang, "An Uncertain Linguistic Multi-Attribute Decision-Making Model Based on Binary Connection Number Distance", Mathematics in Practice and Theory, vol. 42, (2012), pp. 148-152.

[4] J. Q. Wang and J. W. Wu, "Multi-criteria Decision-making Approach Based on the Interval Grey Uncertain Linguistic", Chinese Journal of Management Science, vol. 18, (2010), pp. 107-111.

[5] H. Fang, J. R. Tan and G. F. Yin, "Design scheme evaluation based on improved uncertain-language multi-attribute decision-making method", Computer Integrated Manufacturing Systems, vol. 15, (2009), pp. 1257-1261, 1269.

[6] Y. Liu and Z. P. Fan, “A Group Decision-Making Method with Multi-granularity Uncertain Linguistic Information", Journal of Northeastern University(nature science edition), vol. 30, (2009), pp. 601-604.

[7] X. Yang, S. H. Teng and W. Zhang "Evaluating real estate based on two-tuple linguistic multi-attribute decision making", Application Research of Computers, vol. 27, (2012), pp. 2565-2566, 2574. 
[8] J. P. Li and W. Li, "TOPSIS algorithm for ordinal multi-attribute decision making with incomplete weight information”, Computer Integrated Manufacturing Systems, vol. 19, (2013), pp. 1408-1413.

[9] G. W. Wei, "Two-tuple linguistic multiple attribute group decision making with incomplete attribute weight information", Systems Engineering and Electronics, vol. 30, (2008), pp. 273-277.

[10] J. Liu and S. F. Liu, "Research on the Ranking of Multiple Decision Object for Attribute Value within Interval Numbers”, Chinese Journal of Management Science, vol. 18, (2010), pp. 90-94.

\section{Author}

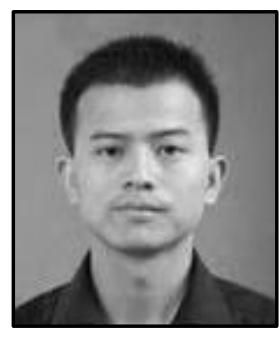

Jian Zhenqiang, doctor, he is working in Economics and Management School of Wuhan University, research direction: Multiple attribute decision. 